\title{
Ensinar e aprender Filosofia \\ num contexto de morte do desejo de filosofar
}

Wanderley J. Ferreira Jr.

Professor Adjunto de Filosofia da Educação na UFG

\section{Resumo}

Reflexão sobre as condições constitutivas do desejo de filosofar e a morte da Filosofia na sociedade atual, apontando para os limites e possibilidades da própria Filosofia. Procura-se determinar, ainda, as possíveis contribuições da Filosofia para a Educação e de que forma repercute no ensino e aprendizado da mesma a morte do desejo de filosofar. Conclui-se, procurando estabelecer quais as exigências que se colocariam à própria Filosofia para que seu ensino não se degenere em mera erudição e repetição idiotizante de conceitos, frases feitas e sistemas.

Palavras-Chaves: Filosofia - Educação - Formação - Ciência.

\section{Résumé}

Réflexion sur les conditions constitutives du désir de philosopher et le décès de la philosophie dans la société actuelle, en indiquant pour les limites et les possibilités de la Philosophie elle-même. Il se cherche à déterminer, encore, les possibles contributions de la philosophie pour l'Éducation et de qu'il forme il réverbère dans l'enseignement et l'apprentissage du le même le décès du désir de philosophie. Il se conclut, en cherchant à établir lequel les exigences qui se placeraient à la philosophie elle-même pour qui son enseignement ne se dégénère pas dans simple répétition idiot de concepts, phrases faites et systèmes.

Mots-Clé: Philosophie - Éducation - Formation - Science. 
questão do que e como ensinar e aprender a filosofar ocupa
cada vez mais espaço na mídia, nos simpósios, nos colóquios de
Filosofia e nas teses acadêmicas. Contudo, dizem alguns “especialistas”, a questão do ensinar e aprender Filosofia não possui o rigor e a pureza próprios das grandes questões filosóficas, uma vez que remete para problemas e áreas do conhecimento que extrapolam os limites da indagação filosófica, além de exigir que o filósofo "suje suas mãos" e polua sua mente com problemas ligados à educação e às chamadas ciências humanas (cf. MORAIS, 1980, p. 120), que nem sequer conseguem justificar cientificamente suas proposições ou alcançar algum resultado consensual.

O fato é que existiria no meio filosófico de hoje, como constata o prof. Newton A. Von Zuben (1990, p. 11), um certo "medo de lidar com questões ligadas à educação, medo muitas vezes travestido de descaso". Muitos estudiosos e professores de Filosofia consideram que, diante do caráter polissêmico, polidisciplinar e ideológico do fenômeno da educação, a atitude mais sensata para a Filosofia seria o silenciar, quando não o descaso. Assim, para alguns filósofos profissionais, que a rigor não podem ser considerados filósofos, mas apenas "funcionários da Filosofia" (NIETZSCHE, 1970, p. 42), o processo da educação e a questão do ensino de Filosofia, não possuiriam dignidade e assepsia suficientes para se tornarem objetos de reflexão filosófica.

Contudo, a experiência humana ao longo da história mostra que o filósofo não deve se omitir e deixar de pensar a educação e as questões acerca do ensino da Filosofia com receio de "poluir a mente" ou de comprometer o rigor, a necessidade e a universalidade reivindicados pelo discurso filosófico. A Filosofia sempre possuirá uma vocação pedagógica, comprometendo-se com a formação integral do homem e com seu crescente discernimento acerca de si mesmo e de seu lugar no mundo. Infelizmente, ainda hoje, particularmente em nossas academias, existem aqueles eruditos e intelectuais, homens que não ultrapassam as "opiniões alheias" (cf. NIETZSCHE, 1978, §7), para os quais pensar a educação, o ensino da 
Filosofia, o significado e os pressupostos do ato de educar, seria menos digno que pensar as grandes questões metafísicas acerca do ser, da linguagem e do pensamento, ou o problema do conhecimento ou a justificação lógica das proposições científicas (cf. VON ZUBEN, 1990).

Mas, afinal, o que na educação e no ensino de Filosofia nos incita a pensar? Tal questão assume extrema importância e urgência numa época que supostamente estaria sob o domínio planetário da técnica (Heidegger), e que perdeu o sentido e o significado da própria práxis pedagógica, já que os valores e fins, aos quais ela necessariamente faz referência, estão extremamente relativizados em uma época na qual a única permanência é a impermanência de todas as coisas, valores e ideias.

Em relação ao ensino e aprendizado de Filosofia, um dos primeiros aspectos a ser considerado é a polissemia do próprio termo Filosofia, que reúne uma gama enorme de atividades intelectuais que não conseguem alcançar o nível mínimo de consenso acerca de seu campo, métodos, problemas, limites e possibilidades. Na realidade, a Filosofia não consegue sequer alcançar o mínimo consenso sobre sua própria definição, seu sentido e sua finalidade. O que essa aparente "galeria de opiniões", essa pluralidade de obras, discursos e tendências têm em comum e que permite caracterizálas como filosóficas? Onde, afinal, encontrar o significado próprio do filosofar? Nos textos dos grandes pensadores e mestres? Ou no cerne da própria vida de onde emergem os enigmas e mistérios que aguçam nossa curiosidade e provocam nosso pensamento?

Infelizmente, o senso comum e a ciência demonstram um certo desdém e descaso para com a Filosofia, desde sua origem entre os gregos. Talvez isso seja resultado da perda e do desvio da essência de nosso próprio êthos, perda que é expressa por Heráclito em apenas três palavras: "Êthos anthrópo daímon" (SOUZA, 2000, fr. 109, p. 100). Heidegger (1987, p. 168) interpreta tal sentença afirmando que ela diz: "o homem habita, na medida em que é homem, na proximidade de Deus". Para ilustrar melhor essa proximidade, Heidegger relembra uma história que Aristóteles relata em Das Partes dos Animais (A 5, 645 a 17): forasteiros curiosos para saber como vivia um grande pensador, aproximam-se da cabana de Heráclito. 
Para surpresa e decepção dos curiosos visitantes, o pensador fazia algo banal e corriqueiro: apenas se aquecia ao fogo. Percebendo o constrangimento de seus visitantes, Heráclito convida-os a entrar: "Entrem, pois também aqui estão presentes os deuses” (HEIDEGGER, 1987, p. 170). Os visitantes querem ver o pensador pensando, não para serem atingidos pelo pensar. Entretanto, o que veem esses visitantes? O pensador fazendo algo bastante comum e banal - aquecendo-se ao fogo. $\mathrm{O}$ pensador revela aqui toda indigência de sua vida, mas em meio a essa indigência ele anuncia a presença dos deuses. Esta palavra, segundo Heidegger, situa a morada (ethos) do pensador e seu agir numa outra luz. Ela diz que:

Também aqui, junto ao forno, neste lugar corriqueiro, onde cada coisa e cada circunstância, cada agir e cada pensar, são costumeiros e banais, isto é, familiares (pois, também aqui), no âmbito do familiar, a coisa é de tal modo, ‘que os deuses estão presentes'. (HEIDEGGER, 1987, p. 171).

Assim, o dizer do pensador diz que é no seio mesmo do mais familiar que se abre ao homem o que não é familiar - a presentificação do Deus, ou seja, a dimensão do sagrado e extra-ordinário. Platão, por sua vez, no diálogo Teeteto, conta a estória de uma jovem camponesa, que vendo Tales cair num poço enquanto caminhava observando o céu, riu e zombou do filósofo. Este preocupava-se em saber o que se passa no céu, mas ignorava o que se passa sob seus pés (PLATÃO, 1987, p. 42).

O fato é que a ciência, o senso comum e alguns que se dizem filósofos exigem da Filosofia o que ela não nos pode dar, eficiência e produtividade. Julgam a Filosofia pelos critérios utilizados para julgar a ciência. Isso é reflexo da perda da compreensão do que significa o próprio filosofar. Passamos a exigir da Filosofia o que ela não nos poder dar - resultados imediatos e úteis.

Devemos compreender, antes de tudo, que a Filosofia é, necessariamente, extemporânea e jamais encontrará ressonância imediata na realidade. Onde tal parece ocorrer, alerta-nos Heidegger, onde a "Filosofia se transformou em moda, ou não há verdadeira Filosofia ou uma verdadeira 
Filosofia foi desvirtuada e violentada segundo propósitos alheios, para satisfazer às necessidades do tempo" (HEIDEGGER, 1969, p. 45). Essa extemporaneidade da Filosofia, que faz com que as pessoas perguntem sempre por sua utilidade e definição, deve-se talvez a duas razões: "Ou porque a Filosofia se projeta para muito além da atualidade, ou então, porque faz remontar à atualidade o seu passado-presente originário" (HEIDEGGER, 1969, p. 45), que estaria nas experiências originárias do ser, do pensar e da linguagem entre os gregos, que estão parados em nosso futuro.

Agostinho (1991, p. 82) já nos ensinava que "há coisas para serem usufruídas, e outras para serem usadas". Coisas que podem ser usadas são úteis: são meios para um fim exterior a elas. Mas as coisas que são usufruídas nunca são meio para nada. São fins em si mesmos. Elas nos dão prazer. São inúteis, como a Filosofia, como uma sonata de Bach, como um poema. O fato é que toda a tradição do pensamento filosófico ocidental, de Platão a Heidegger, mostra-nos que a Filosofia não precisa justificar sua existência atendendo aos interesses e necessidades desse pragmatismo imediatista reinante, mostrando resultados, eficiência e produtividade. Entretanto, ainda são comuns dois tipos de incompreensões acerca dos limites e possibilidades da Filosofia e que repercutem em seu ensino e aprendizado.

Primeiro, sobrecarregamos e superestimamos as possibilidades da Filosofia, exigindo que ela fundamente uma determinada cultura ou simplesmente prepare a revolução. O pernicioso aqui é que as exigências deturpadas que se fazem à Filosofia se apresentam na forma de uma deficiência por parte da Filosofia. De forma irônica, observa Heidegger (1969, p. 47): “Diz-se, por exemplo: deve-se rejeitar a metafísica porque não colaborou na preparação da revolução. Isso é exatamente tão espirituoso, como se alguém dissesse: porque não se pode voar com um torno, há que se destruí-lo".

Em segundo lugar, distorcemos o sentido do esforço do filosofar ao exigir da Filosofia "o fomento e até mesmo a aceleração do dinamismo técnico-prático da cultura no sentido de uma facilitação" (HEIDEGGER, 
1969, p. 48). Ora, devemos antes alertar os nossos alunos e leitores de que a Filosofia não se constitui como resposta, como posse, doutrina ou dogma, mas se nutre do diálogo, da dúvida, da admiração e da recusa do já feito.

Refletir sobre o ensino de Filosofia nos leva também a perguntar como se dá o processo de ensino-aprendizagem em Filosofia no interior de uma instituição estatal, por exemplo. Como poderemos fazer da Filosofia uma busca radical pela verdade, um verdadeiro exercício de resistência ao saber e à ordem instituídos, se ela hoje se limita à figura de professores e alunos de Filosofia? Qual deveria ser a tarefa da Filosofia e de que forma realizá-la no âmbito de seu ensino-aprendizado em nossas escolas e universidades? A Filosofia, como afirma o prof. Newton A. Von Zuben (1990, p. 14), exige a explicitação da estrutura da própria questão, que sempre estabelece o âmbito onde se inscreverá a "resposta". Ora, questionar, além de caracterizar a atividade própria da Filosofia enquanto um caminho, onde a busca do caminho é o próprio caminho, constitui-se no modo de ser próprio de um ente específico, o homem.

O fato é que a Filosofia quer nos ensinar que na "atitude natural" (Husserl) impera uma consciência dogmática e ingênua que postula sem maiores problemas a existência de um mundo fora da consciência, que pode ser conhecido mediante a representação. Para superar essa atitude natural que nos prende a um realismo ingênuo, é necessária uma relação de estranhamento entre o indivíduo e sua realidade imediata. Contudo, essa exigência de retração do filósofo face à realidade não significa abandono da realidade; ao contrário, ele toma distância para melhor compreender o sentido dessa realidade, retomando-a agora como experiência pensada.

Merleau-Ponty (1988, p. 9) vai na mesma direção ao dizer que é

[...] impossível negar que a Filosofia coxeia. Habita a história e a vida, mas quereria instalar-se no seu centro, naquele ponto em que são advento, sentido nascente. Sente-se mal no já feito. Sendo expressão, só se realiza renunciando a coincidir com aquilo que exprime e afastando-se dele para lhe captar o sentido. É a utopia de uma posse à distância. 


\section{Ensinar Filosofia em tempo de morte do desejo de filosofar}

Com a queda de alguns dogmas positivistas (determinismo, mecanicismo, atomismo) alicerçados no paradigma newtoniano-cartesiano e o advento do paradigma da ordem a partir da desordem, do ruído, descobriu-se que o microscópico não é simples, mas complexo. Por trás dessa aparente complexidade, não existem leis e princípios simples, mas níveis diferentes de complexidade, fenômenos caóticos imponderáveis e imprevisíveis, descontínuos, que embaralham a classificação tradicional das diversas ciências. Ora, essa nova configuração do conhecimento, que exige uma concepção mais sistêmica, holística e interdisciplinar, deve repercutir não apenas na forma em que se ensina e se aprende Filosofia em nossas salas de aula, mas também na determinação do caráter, dos limites e possibilidades dos conteúdos a serem ensinados e suas possíveis contribuições ao processo de formação humana e demais ciências, particularmente às chamadas ciências humanas.

Torna-se cada vez mais consensual no âmbito das Ciências Humanas e da Filosofia a necessidade de "articulação entre as duas ordens de discurso, o científico e o filosófico - sem a pretensão de se reduzir um ao outro". (VON ZUBEN, 1990, p. 17-18). Não se pode negar também que existe um certo consenso em considerar que tanto na Filosofia quanto na Educação o que está em jogo em último caso é o homem, ou seja, a questão antropológica acerca da condição humana, do modo de ser do homem. Reportando-nos a uma passagem de Paul Ricoeur, podemos considerar que a Filosofia e as ciências da educação expressam "a preocupação em reencontrar em nós mesmos aquela parte, aquele aspecto que não pode ser objeto de ciência" (RICOEUR, 1990, p. 16, apud VON ZUBEN, 1990, p. 18). Trata-se de recuperar aquilo que em nós é sujeito. Caberia, portanto, à reflexão filosófica explicitar os pressupostos, limites e possibilidades das Ciências da Educação "para inteirar-se do solo em que elas estão construídas" (cf. RICOEUR, idem, apud VON ZUBEN, 1990, p. 18).

Outro aspecto a ser considerado numa reflexão sobre o que e como ensinar a título de Filosofia, é a exigência de que antes seja esclarecido para 
nós mesmos e para nossos alunos qual o caráter e quais os elementos constitutivos do desejo de filosofar. E em que medida esse desejo de filosofar encontra-se em perigo em nossa época. Uma época indigente, que não pensa, mas apenas planifica e calcula. Em tal época, a Filosofia chega a seu fim mediante sua realização nas Ciências tecnizadas (cf. HEIDEGGER, 1987) e o espírito degrada-se em inteligência instrumental (cf. HEIDEGGER, 1969). Vivenciamos, assim, o mal-estar de uma época que dificulta uma relação mais essencial, originária e interativa com as coisas, o mundo e os outros, uma vez que tudo se mostra em sua mera disponibilidade ao cálculo. Até mesmo o homem é visto, muitas vezes, como uma espécie de ruído que deve ser eliminado para uma maior otimização do sistema. Nesse sentido, perguntamos: numa sociedade em que as imagens hiper-realizam o real, mediante um processo de desreferenciação do objeto e des-substancialização do sujeito, na qual a única coisa para pensar é a ausência de pensamento, como recuperar ou salvar o desejo de filosofar?

O pensador francês Alain Badiou (1994, p. 35) em uma de suas conferências brasileiras, intitulada $A$ situação $d a$ Filosofia na contemporaneidade, parte das seguintes questões: "Por que há filósofos? O que é um filósofo, considerado como sujeito empírico? Como se caracteriza o desejo de Filosofia?" Na tentativa de caracterizar o desejo de filosofar, o pensador aponta quatro condições constitutivas do mesmo: a revolta, a lógica, a universalidade e a aposta - o risco. Ora, mas como ensinar e aprender Filosofia numa época que sistematicamente mata o desejo de filosofar?

Como fazer nossos alunos entender que o desejo de filosofar comporta e exige algo aparentemente paradoxal, ou seja, uma certa "revolta lógica"? Revolta, sim, porque a Filosofia enquanto discurso radical e crítico sempre coloca em questão o conhecimento, os valores e ideais instituídos. Para o filósofo muitas vezes "é melhor ser Sócrates descontente do que ser um porco satisfeito" (cf. BADIOU, 1994, p. 36). Pois bem, a Filosofia é descontente com o mundo tal como ele é. É descontente até consigo mesma, pois tem o hábito de pensar contra si mesma. Mas essa rebeldia da Filosofia, 
que pode até ajudar em sua aceitação pelos mais jovens, não é uma rebeldia sem causa, uma revolta que apenas desconstrói e nega o instituído. A revolta constitutiva do desejo de filosofar exige, por paradoxal que possa parecer, uma lógica. É uma revolta fundada na discussão normatizada pela razão. A revolta da Filosofia busca a construção de argumentos racionais para justificar sua crítica radical. É uma revolta que erige uma lei para si mesma balizando-se pelo bom senso e pelos princípios da racionalidade, que certamente extrapola os limites da razão instrumental científica.

Mas o desejo de filosofar também se alimenta de uma certa tensão entre a universalidade/necessidade pretendida pelo discurso filosófico e a idéia de acaso, de aposta, de imponderável. Nesse sentido, podemos considerar que há na Filosofia um grande desejo de universalidade, na medida em que ela se dirige a todo pensamento e a todo homem, sem exceção.

Ela [a Filosofia] não é nacional, mas internacional. Ela quer ultrapassar toda cultura particular, toda tradição. Seu verdadeiro destino não é a sala de conferência, mas a rua, a praça pública, o mundo inteiro [...] A Filosofia se dá para todo pensamento; ela se dá para o príncipe e para o escravo. (BADIOU, 1994, p. 38)

Entretanto, ao mesmo tempo em que o desejo de Filosofia é o desejo do universal, é também sentimento do risco e do acaso. Ou seja, a Filosofia só pode aspirar à universalidade se apostar no acaso, no engajamento, no risco, na imprevisibilidade do encontro. O desejo de filosofar é, portanto, perpassado por uma revolta, recusa a ficar instalado e satisfeito. Uma recusa que exige uma lei, uma norma, uma lógica que expressa o desejo de uma razão coerente. Mas o desejo de filosofar também se nutre do universal e do necessário, da recusa ao particular e imediato. Contudo, essa universalidade é buscada mediante a aposta no risco, no engajamento, no acaso e na experiência irrepetível do encontro.

Após essa breve caracterização dos elementos constituintes do desejo de filosofar, uma constatação se impõe: o mundo contemporâneo é oposto 
ao desejo de filosofar. Ele nega e se opõe veementemente aos quatro componentes do desejo de Filosofia. Nosso mundo, dirá Badiou, não gosta da revolta nem da crítica. "É um mundo que crê na gestão e na ordem natural das coisas [...]. Ele pede a cada um para adaptar-se. É um mundo do simples cálculo individual” (BADIOU, 1994, p. 48). Nosso mundo é avesso à coerência racional, está submetido à lógica de imagens e signos que simulam o real. Esse mundo das imagens, mundo da mídia, é instantâneo e incoerente. É um mundo muito rápido e sem memória, efêmero e fugaz. Onde a única permanência é a impermanência. Em tal mundo das imagens, em que a forma se sobrepõe ao conteúdo, é muito difícil sustentar uma lógica do pensamento.

Outro elemento constitutivo do desejo de filosofar que perde espaço em nosso mundo é a universalidade, uma vez que a única universalidade que ele conhece é a do dinheiro, a universalidade daquilo que Marx chamava de equivalente geral. Fora da universalidade do mercado e da moeda, cada um está encerrado em sua tribo. Cada um defende sua particularidade. Em nosso mundo a falsa universalidade do capital é contraposta ao gueto das culturas, etnias, classes, religiões (cf. BADIOU, 1994). Paradoxalmente, ao mesmo tempo que assistimos à globalização das leis de mercado, emergem demandas de grupos e etnias reivindicando maior inserção social com respeito às suas particularidades e diferenças. Ou seja, é cada vez maior a exigência de uma ética da diversidade e das singularidades que coloque em xeque a visão de homem, enquanto sujeito e razão universal abstrata, em relação à qual se podem referenciar certos imperativos, direitos e deveres, tidos também como universais.

Por outro lado, a aposta, o acaso, o risco, o engajamento, também são negados e dissimulados pelo mundo do cálculo, da previsão, da segurança, no qual vence o mais adaptado. Badiou considera que vivemos em um mundo obcecado pela segurança, "um mundo onde cada um deve, o mais cedo possível, calcular e proteger o seu futuro. É um mundo da carreira e da repetição. Um mundo onde o acaso é perigoso. Um mundo onde não devemos nos abandonar aos encontros" (BADIOU, 1994, p. 39).

Podemos então considerar que nosso mundo contemporâneo é oposto 
ao desejo de Filosofia. Nele a Filosofia está ameaçada, não encontra direito de cidadania. A Filosofia encontra-se tão marginalizada que sua principal questão na atualidade é saber como ela pode proteger e salvar o desejo de filosofar. Contudo, a Filosofia não pode se esgotar num discurso que insiste em mostrar sua "utilidade" ou cair num vitimismo, fechando-se sobre si mesma. Na realidade, se a Filosofia hoje tem de justificar sua existência e necessidade, o problema não é da Filosofia, mas de uma época na qual acontecem a massificação e a bestialização do homem, a idolatria do Estado, a crença de que a felicidade está diretamente relacionada à propriedade e, por fim, a morte do desejo de filosofar e de suas condições: a revolta, a lógica, a universalidade e a aposta, o risco.

Em A Filosofia na época trágica dos gregos, Nietzsche (1978, p. 53) nos alerta que:

Um tempo que sofre da assim chamada cultura geral, mas sem civilização e sem unidade de estilo em sua vida não saberia fazer nada de correto com a filosofia, ainda que ela fosse proclamada pelo gênio da verdade em pessoa nas ruas e nas feiras.

De fato, não temos uma civilização, nossas escolas e universidades formam profissionais, homens de segunda mão, bestas do trabalho, "incompetentes sociais" (Chauí), mas não homens com estilo, com caráter e força para fazer de sua existência um constante exercício de criação e afirmação da vida, mesmo na dor e no sofrimento. O que vemos? Por todos os lados, o chamamento: adaptem-se - é a única coisa que nos resta a fazer diante da ditadura de um pensamento único que proclama a morte das utopias e da consciência histórica, eternizando o presente. Em tal tempo, a Filosofia apresenta-se, no dizer de Nietzsche (1978, p. 53), como

[...] monólogo erudito de um passeador solitário, [...] ou oculto segredo de gabinete reduzido a inofensiva tagarelice entre anciãos acadêmicos. Ninguém ousa cumprir a lei da Filosofia em si mesma, ninguém vive filosoficamente [...]. Todo filosofar moderno e contemporâneo está política e 
policialmente limitado à aparência erudita, por governos, igrejas, academias, costumes, moda...

$\mathrm{Na}$ realidade, na sociedade do espetáculo, na qual as imagens hiper-realizam o real, a Filosofia, a reflexão, não tem direitos. Contudo, se deixássemos a Filosofia falar, era poderia nos dizer:

Povo miserável! É culpa minha se em vosso meio vagueio como uma cigana pelos campos e tenho de me esconder e disfarçar, como se fosse eu a pecadora e vós meus juízes? Vede minha irmã - a arte. Ela está como eu, caímos entre bárbaros e não sabemos nos salvar. Aqui nos falta, é verdade, justa causa, mas os juízes diante dos quais encontraremos justiça tem também jurisdição sobre vós, e vos dirão: Tendes antes uma civilização, e então ficareis sabendo o que a Filosofia quer e pode. (NIETZSCHE, 1978, p. 53)

Apesar das circunstâncias adversas ao desejo de filosofar, a Filosofia deve preservar seu senso crítico e sua revolta e hábito de pensar até mesmo contra si. Ela não pode abrir mão de seu papel desmistificador diante das ideologias vigentes, que teimam em passar uma visão homogênea, mascarando as contradições reais de nossa realidade. Através de seu ensino e aprendizado, a Filosofia pode e deve contribuir para que possamos tornar explícitos os mecanismos que nos fazem tomar a aparência pela realidade, isso certamente exigiria um processo de desbanalização do banal, que deveria levar o aluno a se estranhar com sua própria realidade imediata e experiências fragmentárias do senso comum.

Devemos ainda, enquanto educadores e professores de Filosofia, atentar para certas exigências que são hoje colocadas a ela. Exigências que certamente devem repercutir no modo em que se aprende e se ensina Filosofia em nossas escolas e universidades. Há uma certa exigência de que a Filosofia seja "uma Filosofia do evento, antes que da estrutura. Que a Filosofia seja uma Filosofia [...] da singularidade universal. Quer dizer: daquilo que é, a cada vez, absolutamente singular, como um poema, um teorema, uma paixão, uma revolução; e contudo, para o pensamento, 
absolutamente universal" (BADIOU, 1994, p. 43). A Filosofia deve ainda utilizar uma língua flexível. "Uma língua capaz tanto de citar e interpretar um poema como de citar e interpretar um axioma ou um teorema. Uma língua que circule entre o equívoco poético e a transparência científica" (BADIOU, 1994, p. 44).

A Filosofia deve, assim, articular uma linguagem que the permita transitar pelas fórmulas científicas e pela lógica, pelos equívocos do poema e da arte, pelo acaso do desejo e encontros e pela política, enquanto criação de novas formas de convívio social. Isso pressupõe que a Filosofia tem que abrir mão de um conceito unívoco, universal e necessário de verdade. Ela deve admitir diferentes tipos de verdades pronunciadas e legitimadas por diferentes narrativas, para nada sacrificar do desejo de filosofar.

\section{Reflexões conclusivas}

Não importa a estratégia de ensino adotada, se um curso de Filosofia é de caráter temático, problematizador ou toma a História da Filosofia como referencial básico. O que importa é que o exercício de ensinar a filosofar consiga realmente levar à autonomia intelectual e a uma cidadania mais ativa e responsável, sem distorcer o pensar e o dizer dos pensadores, nem matar o desejo de filosofar no aprendiz, intoxicando-o com sistemas, conceitos e nomes sem sentido e desvinculados de sua experiência de vida.

Não podemos esquecer, ainda, que se quisermos fazer de nossas aulas uma autêntica experiência filosófica alicerçada no exercício do pensamento crítico e rigoroso, devemos nos libertar da interpretação técnica do pensar e da linguagem hegemônica no Ocidente desde Platão e Aristóteles. Neles não é mais o Ser que determina o dizer e o pensar; ao contrário, doravante, são as leis do pensar (Princípios de identidade, de Não-contradição e da Razão Suficiente) e as regras da gramática que determinam o que é o Ser, concebido como causa e fundamento do ente. O próprio pensar é tido, ali, como uma tékhne, o processo da reflexão é posto a serviço do fazer e do operar (cf. HEIDEGGER, 1987, p. 149). Como resultado dessa interpretação técnica do pensar e da linguagem vivenciamos hoje a 
indigência de uma época que não pensa, mas apenas planifica e calcula em nome da eficiência e produtividade. Uma época na qual o ensino de Filosofia é questionado do ponto de vista de sua utilidade por não atender as demandas do pragmatismo imediatista imposto pelo deus onisciente e onipresente chamado mercado. Como se não bastasse isso, a maioria de nossos alunos, e muitos de nós professores, não mantêm mais uma relação significativa com a linguagem. Não sabemos mais ouvir, ler, escrever e falar. Usamos as palavras como se realmente fossem cápsulas que comportam significados que devem remeter às coisas existentes (a um referente). E se estamos impedidos de manter uma relação essencial com a linguagem, também não conseguiremos pensar, e sem pensar perderemos inevitavelmente contato com o próprio real, que não se reduz aos dados imediatos da experiência sensível.

Como então nessa época de morte do desejo de filosofar, de domínio planetário da técnica, poderemos cumprir a tarefa de ensinar a pensar e falar com significação, numa palavra: filosofar? Certamente ensinar a pensar, falar e até mesmo sentir, compreende um repertório de estratégias e conteúdos que não podem se esgotar na mera transmissão de conhecimentos já adquiridos. Isso porque o que de maior temos a ensinar aos nossos alunos talvez seja o aprender. O grande mestre não ensina nada além do aprender, tornando dis-posto (aberto) o discípulo para novos conhecimentos.

Aquele que verdadeiramente ensina não faz aprender nenhuma outra coisa que não seja o APRENDER [...] No relacionamento do mestre que ensina e dos alunos que aprendem, quando o relacionamento é verdadeiro, jamais entram em jogo a autoridade de quem sabe muito [...] Por causa disso é ainda uma grandeza ser mestre - que é bem outra coisa do que ser um professor célebre. (cf. HEIDEGGER, apud FARIAS, 1985)

Por fim, gostaria de confessar que como professor de Filosofia sintome constrangido quando me deparo com aqueles momentos em que o silêncio é a forma mais originária de dizer. E quantas e quantas vezes não matamos o pensar e mascaramos as condições originárias de determinado 
pensamento (Admiração, Dúvida, Angústia), expondo-o como um corpo de idéias fixas e estabelecidas? $O$ aluno acaba se perdendo na enganosa homogeneidade dos sistemas, sem compreender as reais motivações, adesões e recusas dos filósofos estudados. Enfim, quantos de nós já não caímos na tentação de reduzir a Filosofia às belas citações?

\section{Bibliografia}

AGOSTINHO, Santo. Doutrina Cristã: Manual de exegese e formação cristã. São Paulo: Edições Paulinas, 1991.

BADIOU, Alain. A situação da Filosofia no mundo contemporâneo. In. Para uma nova teoria do sujeito: conferências brasileiras. Rio de Janeiro: Relume-Dumará, 1994.

FARIA, Vitor. Heidegger e o nazismo. Rio de Janeiro : Paz e Terra, 1985.

HEIDEGGER, Martin. Carta sobre o Humanismo. São Paulo: Abril Cultural, 1987.

. Introdução à metafísica. Rio de Janeiro: Tempo Brasileiro, 1969.

. O fim da Filosofia e a tarefa do pensamento. São Paulo: Abril Cultural, 1987.

MERLEAU-PONTY. Les sciences de l'homme et la phénoménologie. Paris: Cours de l'université, 1990.

MORAIS, Régis. Discurso bumano e discurso filosófico na educação. Campinas: Papirus, 1980.

NIETZSCHE, Friedrich. A Filosofia na época trágica dos gregos. In: Obras Incompletas. Trad. Rubens Rodrigues Torres Filho. São Paulo: Abril cultural, 1978.

Le crepuscule des idoles. Tradução: Henri Albert. Paris: Denoel/Gonthier, 1970.

NIETZSCHE, Friedrich. Schopenhauer como Educador. In. Obras Incompletas. Trad. Rubens Rodrigues Torres Filho. São Paulo: Abril cultural, 1978. PLATÃO. Teeteto. Brasília: UnB, 1987.

SOUZA, José Cavalcante de. Os Pré-sócráticos: Fragmentos, Doxografia e Comentários. São Paulo: Ed. Nova cultural, 2000. 
VON ZUBEN, Newton Aquiles. Filosofia e Educação. Aberto, ano 9, n. 45, Jan-Mar. 1990, p. 11-18. 